\title{
Conservative surgery of the mitral valve: a report of the first 100 cases from one unit and one
} surgeon

\author{
A Kenny, C A Fuller, L M Shapiro, F C Wells
}

\begin{abstract}
Objective-To report the first 100 mitral valve repairs performed in a unit with an aggressive approach to conservative mitral valve surgery.
\end{abstract}

Design-Case notes were reviewed retrospectively and patients invited for clinical examination and cross sectional and Doppler echocardiography.

Setting-Tertiary cardiothoracic referral centre.

Patients-Between December 1985 and April 1991 mitral valve repair was carried out on 100 patients (66 males). Patients with pure mitral stenosis were excluded. Sixty seven had degenerative and 15 rheumatic mitral valve disease. Median age was 66 (range 12 to 79) years, with an interquartile range of 59 to 71 years.

Interventions-Operative procedures included annuloplasty ring in 97 , resection of the posterior leaflet in 67 , resection of endocarditic portion of posterior leaflet in four, commissurotomy in six, and correction of anterior leaflet abnormalities in seven. Thirty nine concomitant cardiac procedures were performed in 32 patients. Six operations were emergencies, and three of these required concomitant procedures.

Main outcome measures-Mortality, operative failure rate, patients' functional state and degree of residual mitral regurgitation, incidence of thromboembolism, and endocarditis.

Results-Follow up ranged from one to 59 months, median 14 months, and an interquartile range of four to 23.5 months. Early mortality was $1 \%$, late mortality $5 \%$, and there was a $2 \%$ reoperation rate. Eighty four patients had moderate to severe mitral regurgitation preoperatively. At follow up mitral regurgitation was absent or mild in 78 . Eighty six patients were in New York Heart Association (NYHA) class I-II at follow up compared with 80 in NYHA class III-IV preoperatively. There were no thromboembolic events.

Conclusion-This study shows that satisfactory results can be obtained with mitral valve repair in a fairly elderly population with a high incidence of concomitant cardiac disorders. We suggest that these encouraging results will lead to earlier mitral valve repair in mitral regurgitation.

\section{(Br Heart J 1992;68:505-9)}

Reconstructive mitral valve surgery for mitral regurgitation was first described in $1957 . .^{12}$ In the United States and Europe, however, mitral valve replacement has, until recently, been the standard operation for mitral regurgitation after the first successful mitral prosthetic valve implantation in $1961 .^{3}$ Some European centres continued to favour mitral valve reconstruction, with Carpentier's group pioneering techniques of repair based on functional analysis of the mitral valve. ${ }^{4}$ The satisfactory late results from these centres has stimulated a wider interest in repair techniques in recent years. ${ }^{56}$ Mitral valve repair techniques are complex and the well described associated learning curve has deterred many surgeons and cardiologists from developing a service. ${ }^{78}$ We review our early experience with 100 mitral valve repairs performed by one surgeon between December 1985 and April 1991.

\section{Patients and methods PATIENTS}

Mitral valve repair for mitral regurgitation was started in our institution in December 1985 and during the period to April 1991, 100 patients underwent Carpentier techniques of mitral valve repair by one surgeon. Ninety four patients had pure mitral regurgitation and six had mixed mitral valve disease. Patients with pure mitral stenosis were excluded from the study. Sixty six were male and 34 were female. Median age was 66 (range 12 to 79 ) years with an interquartile range of 59 to 71 years. This represents a more elderly population than in most reported series. Our use of mitral valve reconstruction has increased each year as experience with the technique was gained (fig 1). Table 1 lists the causes of mitral regurgitation in our patients.

Preoperative New York Heart Association
Papworth Everard,

Accepted for publication

11 May 1992 
Figure 1 Mitral valve repair $v$ replacement over the period 1985-1991 (four months only for 1991).

Table 1 Causes of mitral regurgitation

\begin{tabular}{ll}
\hline $\begin{array}{l}\text { Aetiology of } \\
\text { valve lesions }\end{array}$ & $\begin{array}{l}\text { No of } \\
\text { patients }\end{array}$ \\
\hline Degenerative & 67 \\
Rheumatic & 15 \\
Ischaemic & 7 \\
Endocarditis & 8 \\
Congenital & 1 \\
Functional & 1 \\
Infiltrative & 1 \\
\hline
\end{tabular}

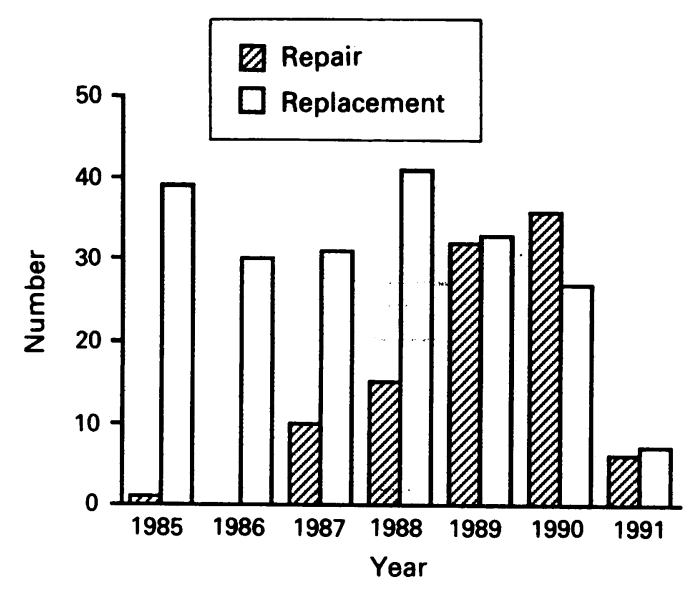

(NYHA) functional classification was ascertained by examination of the patients' records. Ninety per cent of patients underwent preoperative, and all patients postoperative cross sectional and Doppler echocardiography to determine the severity of mitral regurgitation. The severity of mitral regurgitation was assessed by cardiac catheterisation in the 10 patients who did not have preoperative echocardiography.

At follow up, NYHA classification, clinical examination, cross sectional and Doppler echocardiogram to determine mitral valve area, degree of mitral regurgitation, and left atrial size were assessed. Mitral regurgitation was graded by pulsed Doppler assessment of the depth of jet into the left atrium and intensity of the regurgitant signal, with the scoring system described by Pons-Llado et $a l .{ }^{9}$ This is a sensitive method of detecting and assessing the severity of mitral regurgitation.

\section{METHODS}

Intraoperative examination of the mitral valve allowed classification of patients according to Carpentier's three functional categories based on leaflet function-namely, normal leaflet motion, prolapsed leaflet, and restricted leaflet motion. ${ }^{4}$ Table 2 summarises the functional type of mitral valve dysfunction and the underlying anatomical lesions.

Type 1 mitral regurgitation was treated with a prosthetic ring annuloplasty. Mitral regurgitation associated with increased leaflet mobility was treated by leaflet resection, chordal shortening, or chordal transposition. In type 3 disease increased leaflet mobility was attained by commissurotomy, chordal division, chordal excision, and division of the papillary muscles. In type 2 and 3 mitral regurgitation a prosthetic remodelling ring annuloplasty was usually required. Ninety seven patients were treated with a prosthetic ring annuloplasty. Seven patients had abnormalities of the anterior leaflet corrected.

Thirty nine concomitant cardiac procedures were performed in 32 patients. In patients undergoing concomitant coronary artery bypass grafting (CABG) a mean of two grafts, range one to three, were performed. Six patients were operated on as emergencies; five of these were over 65 years old and three had
Table 2 Functional classification of valve dysfunction and underlying anatomical lesions (sum of lesions $>$ number of patients due to associated lesions

\begin{tabular}{|c|c|c|}
\hline Valve dysfunction & & $\begin{array}{l}\text { No of } \\
\text { patients }\end{array}$ \\
\hline $\begin{array}{l}\text { Type } 1 \text { Normal leaflet motion: } \\
\text { Annular dilatation/deformation } \\
\text { Leaflet perforation }\end{array}$ & & $\begin{array}{r}20 \\
18 \\
2\end{array}$ \\
\hline $\begin{array}{l}\text { Type } 2 \text { Leaflet prolapse: } \\
\text { Prolapse PL } \\
\text { Chordal rupture } \\
\text { Chordal elongation } \\
\text { Intact chordae } \\
\text { Ruptured papillary muscle }\end{array}$ & $\begin{array}{r}60 \\
3 \\
6 \\
1\end{array}$ & $\begin{array}{l}74 \\
70\end{array}$ \\
\hline $\begin{array}{l}\text { Prolapse } A L \\
\text { Chordal rupture } \\
\text { Ruptured papillary muscle }\end{array}$ & 1 & 2 \\
\hline $\begin{array}{l}\text { Prolapse } A L \text { and } P L \\
\text { Chordal elongation } \\
\text { Chordal rupture }\end{array}$ & $\begin{array}{l}1 \\
1\end{array}$ & 2 \\
\hline $\begin{array}{l}\text { Type } 3 \text { Restricted leaflet motion: } \\
\text { Commissural fusion } \\
\text { Chordal fusion } \\
\text { PL } \\
\text { AL }\end{array}$ & $\begin{array}{l}1 \\
1\end{array}$ & 6 \\
\hline
\end{tabular}

PL, posterior leaflet; $A L$, anterior leaflet.

concomitant cardiac procedures, CABG in one and aortic valve replacement (AVR) in two. Eighteen patients in total underwent CABG, 15 of these patients were over 65 years old and represented a high risk subgroup. Tables 3 and 4 list details of the surgical procedures and associated cardiac procedures performed. Anticoagulation with warfarin was used for three months only in those patients in sinus rhythm, to allow endothelialisation of the ring, but continued indefinitely in patients with persistent atrial fibrillation or mechanical aortic valve prosthesis.

Eight patients with endocarditis underwent mitral valve repair and these represent an interesting subgroup. Two patients had perforation of the anterior leaflet repaired by oversewing in one and patch repair in the second. Four patients underwent resection of the endocarditic portion of the posterior leaflet and an annuloplasty ring was inserted in three. In the remaining two patients the endocarditis had healed and a quadrangular resection of the posterior leaflet and ring annuloplasty were performed.

Table 3 Operation details

\begin{tabular}{lrl}
\hline Operative procedures & $\begin{array}{l}\text { No of } \\
\text { patients }\end{array}$ \\
\hline $\begin{array}{l}\text { Prosthetic ring annuloplasty } \\
\quad \text { Carpentier }\end{array}$ & 97 \\
$\quad \begin{array}{l}\text { Sliding annuloplasty (Carpentier) } \\
\text { Duran-Medtronics flexible ring }\end{array}$ & 1 & \\
PL Resection & 3 & \\
$\quad$ Quadrangular resection & 66 & \\
$\quad$ Double resection & 1 & \\
$\quad$ Resection endocarditic portion & 4 & \\
Chordal shortening AL & & 2 \\
Reattachment of chordae to AL & \\
Transposition of chordae & 1 \\
$\quad$ PL & & 1 \\
$\quad$ Patch repair AL & 1 \\
Commissurotomy & & 2 \\
Division of papillary muscles & 6 \\
Chordal division & \\
$\quad$ PL & & 1 \\
AL & & 1 \\
\hline PLision of chordae & 2
\end{tabular}

$\mathrm{PL}$, posterior leaflet; $\mathrm{AL}$, anterior leaflet. 
Table 4 Cardiac procedures concomitant with mitral valve repair

\begin{tabular}{lr}
\hline Concomitant procedures & No \\
\hline CABG & 18 \\
AVR & 12 \\
ASD Repair & 1 \\
Tricuspid annuloplasty & 4 \\
Tricuspid valvotomy & 1 \\
Aortic annulus decalcification & 1 \\
Posterior annulus decalcification & 3 \\
Enlargement of aortic root & 1 \\
Replacement of aortic root & 1
\end{tabular}

CABG, coronary artery bypass grafts; AVR, aortic valve replacement; ASD, atrial septal defect.

\section{Results}

Ninety three of the 100 patients in this series were reviewed; six had died and one had undergone reoperation and valve replacement. Follow up ranged from one to 59 months, median 14 months, with an interquartile range of four to 23.5 months.

\section{MORTALITY}

One hospital death occurred in a patient with amyloid infiltrative cardiomyopathy as part of extensive systemic amyloidosis shown at post mortem examination. This had been undiagnosed preoperatively and may therefore have been an inappropriate referral for mitral valve repair.

There were five late deaths, three of which were not valve related. Table 5 summarises clinical details and causes of death of the patients who died.

\section{REOPERATION}

Two patients required reoperation, in one at seven months after repair it was found at reoperation that the original repair was intact but that there was fresh chordal rupture to the anterior leaflet. The second patient underwent reoperation and mitral valve replacement for prosthetic ring dehiscence and paraprosthetic leak detected at the routine follow up examination performed for this study.

\section{ANTICOAGULANT RELATED HAEMORRHAGE}

One patient on long-term warfarin treatment for an associated mechanical aortic valve prosthesis died from intracerebral haemorrhage when undergoing treatment for bacterial endocarditis (table 5). A second patient developed a haemorrhagic cerebrovascular accident one week after repair and has a residual dense left hemiplegia.

THROMBOEMBOLISM

There were no documented thromboembolic events reported in this series.

\section{ENDOCARDITIS}

Two patients died after developing new bacterial endocarditis after operation (table 5). One patient, already mentioned, had an associated mechanical aortic valve prosthesis, presented with bacterial endocarditis four months after operation, and died from an intracerebral haemorrhage. The second patient developed endocarditis at two months after repair.

\section{FUNCTIONAL STATE OF PATIENTS AND DOPPLER} ECHOCARDIOGRAPHY

Mitral regurgitation was graded as severe or moderate to severe in 84 patients before operation; at follow up mitral regurgitation was absent to trivial or mild in 78. Eighty patients were in NYHA class III-IV before operation compared with 86 patients in NYHA class I-II after mitral valve repair. All but four patients had improved by at least one NYHA class. Figure 2 graphically shows the improvement in mitral regurgitation and patient functional state after operation.

At follow up six patients were in NYHA class III and echocardiography showed poor global left ventricular function with trivial to mild mitral regurgitation. Three of these patients had poor left ventricular function before operation, three had been in NYHA class IV, and three in NYHA class III.

One patient had moderate to severe mitral regurgitation as a result of ring dehiscence and paraprosthetic leak. Valve replacement was required. Eight patients were noted to have moderate transvalvar mitral regurgitation and one had apparent paraprosthetic regurgitation. All of these patients were symptomatically well, with six in NYHA functional class I and two in NYHA class II.

We noted paradoxical or impaired septal motion on echocardiography in all but two

Table 5 Clinical details of valve ${ }^{\star}$ and non-valve related mortality

\begin{tabular}{|c|c|c|c|c|c|c|c|}
\hline Cause of death & Sex & Age & $\begin{array}{l}\text { Months } \\
\text { after } \\
\text { operation }\end{array}$ & $\begin{array}{l}\text { Aetiology of } \\
M V D\end{array}$ & Procedures & $\begin{array}{l}\text { NYHA } \\
\text { class } \\
\text { before } \\
\text { operation }\end{array}$ & $\begin{array}{l}\text { Mitral } \\
\text { regurgitation } \\
\text { before } \\
\text { operation }\end{array}$ \\
\hline $\begin{array}{l}\text { Cerebral* haemorrhage } \\
\text { (on warfarin) }\end{array}$ & $\mathbf{M}$ & 51 & 4 & Rheumatic & $\begin{array}{l}\text { Ring } \\
\text { AVR }\end{array}$ & I & Mild to moderate \\
\hline Endocarditis ${ }^{\star}$ & $\mathbf{M}$ & 73 & 2 & Degenerative & PL resection of ring & IV & Severe \\
\hline Myocardial infarct & W & 72 & 4 & Degenerative & $\begin{array}{l}\text { PL resection of ring } \\
\text { CABG }\end{array}$ & IV & Severe \\
\hline Myocardial failure & $\mathbf{M}$ & 68 & 2 & Rheumatic & $\begin{array}{l}\text { Ring } \\
\text { AVR }\end{array}$ & IV & Mild to moderate \\
\hline Myocardial failure & $\mathbf{M}$ & 69 & 2 & Degenerative & PL resection of ring & III & Severe \\
\hline $\begin{array}{l}\text { Left ventricular failure } \\
\text { (amyloid) }\end{array}$ & $\mathbf{W}$ & 59 & 1 Day & Infiltrative & Ring & III & Moderate \\
\hline
\end{tabular}

Footnotes as for table 4. MVD, mitral valve disease; PL, posterior leaflet. 
Figure 2 Mitral regurgitation and NYHA classification before and after valve repair. Sev, severe; $M /$ Sev, moderate to severe; Mod, moderate; $M / M$, mild to moderate; Abs/T, absent or trivial.
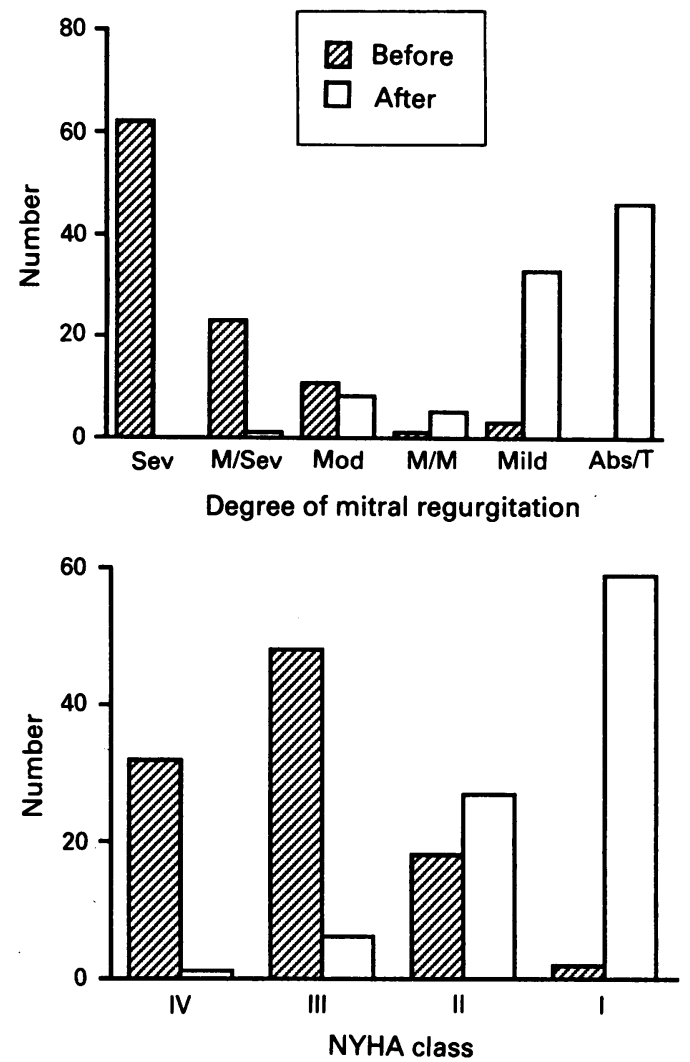

patients and this was unrelated to the type of annuloplasty ring used. This finding is unexplained and to the best of our knowledge not reported in other series of mitral valve repairs.

\section{Discussion}

The now well recognised limitations of prosthetic and bioprosthetic valves have stimulated a renewed interest in techniques of mitral valve repair.

Mitral valve repair has been shown to be durable ${ }^{56}$ and valve related complications are low. ${ }^{5111}$ Preservation of the mitral valve, with intact subvalvar apparatus (chordae tendineae and papillary muscles) has been shown in the laboratory and clinically to preserve left ventricular function. ${ }^{1213}$ There have been no randomised trials comparing mitral valve repair and replacement in mitral regurgitation; however, several comparative case matched studies report improved survival with mitral valve repair. ${ }^{101415}$

Mitral valve replacement in acute ischaemic mitral regurgitation has a poor prognosis with hospital mortalities reported as high as $45 \%{ }^{16}$ Rankin et al and Hickey et al reported improved operative survival after mitral repair rather than replacement in ischaemic mitral regurgitation. ${ }^{17}{ }^{18}$ Likewise Kay et al showed improved long and short-term survival especially in patients with reduced ejection fraction. ${ }^{19}$

There is evidence, therefore, that conservation of the mitral valve has advantages over valve replacement and is now accepted by many as the operation of choice, when possible, in mitral valve disease.

We had one $(1 \%)$ hospital death in this series compared with $1.5 \%$ to $8.5 \%$ reported in other series with similarly aged patient populations. $^{71120-22}$ The late mortality of $5 \%$ in this medium term follow up also compares favourably with other series of similar follow up. ${ }^{21-23}$

The reoperation rate of $2 \%$, similar to that experienced by Cosgrove et $a l,{ }^{7}$ shows that the learning curve in this series was not problematical and superior to rates of $7 \%$ and $8 \%$ in other series with similar population groups and follow up periods. ${ }^{2123}$ There have been no reports of thromboembolic events in our series and it is well accepted that thromboembolism is much lower than with mitral valve replacement. Obstruction of the left ventricular outflow tract due to systolic anterior motion of the mitral valve has been reported after mitral valve repair ${ }^{2425}$ but was not detected in this series. The occurrence of new endocarditis after reconstruction in two patients is similar to that experienced by Cohn et al but higher than in most reported series where the incidence of late endocarditis approaches zero. ${ }^{21}$ This is lower, however, than the $3 \%$ to $6 \%$ incidence of late endocarditis after mitral valve replacement. $^{2627}$

There was no recurrence of endocarditis in the eight patients who underwent repair for mitral regurgitation secondary to mitral valve endocarditis.

Of the five symptomatic patients with poor left ventricular function and no evidence of mitral valve dysfunction, three had evidence of left ventricular dysfunction before operation and earlier intervention may have prevented the development of irreversible left ventricular damage.

Our early experience of mitral valve repair techniques has shown that satisfactory results can be obtained even in elderly high risk groups. We would hope that these encouraging results will lead to earlier mitral valve repair in mitral regurgitation, before the start of irreversible left ventricular failure.

1 Lillehei CW, Gott VL, DeWall RA, Varco RL. Surgical correction of pure mitral insufficiency by annuloplasty under direct vision. Lancet 1957;77:446-9.

2 Merendino KA, Bruce RA. One hundred and seventeen surgically treated cases of valvular rheumatic heart diseases: with preliminary report of two cases of mitra regurgitation treated under direct vision with aid of a pump oxygenator. JAMA 1957;64:749-55.

3 Starr A, Edwards ML. Mitral replacement: clinical experience with a ball-valve prosthesis. Ann Surg 1961; 154:726-40.

4 Carpentier A Cardiac valve surgery-the "French correction". J Thorac Cardiovasc Surg 1983;86:323-37.

5 Deloche A, Jebra VA, Relland JY, et al. Valve repair with Carpentier techniques. The second decade. J Thorac Cardiovasc Surg 1990;99:990-1001.

6 Carpentier A, Chauvaud S, Fabiani JN, et al. Reconstructive surgery of mitral valve incompetence ten year appraisal $J$ Thorac Cardiovasc Surg 1980;79:338-48.

7 Cosgrove DM, Chavez AM, Lytle BW, et al. Results of mitral valve reconstruction. Circulation 1986;74:182-7.

8 Antunes MJ, Colson PR, Kinsley RH. Mitral valvuloplasty: a learning curve. Circulation 1983;68(suppl II):1170-5.

9 Pons-Llado G, Carreras-Costa F, Ballester-Rodes M, Auge Sampera JM, Crexells-Figueras C, Oriol-Palou A. Doppler patterns of left atrial flow in mitral regurgitation. Am J Cardiol 1986;57:806-10.

10 Perier P, Deloche A, Chauvaud S, et al. Comparative evaluation of mitral valve repair and replacement with Starr, Björk, and porcine valve prostheses. Circulation Starr, Björk, and

11 Galloway AC, Colvin SB, Baumann FG, et al. A comparison of mitral valve reconstruction with mitral valve replacement: intermediate-term results. Ann Thorac Surg 1989;47:655-62.

12 Goldman ME, Mora F, Guarino T, Fuster V, Mindich BP. 
Mitral valvuloplasty is superior to valve replacement for preservation of left ventricular function: an intraoperative two-dimensional echocardiographic study. J Am Coll Cardiol 1987;10:568-75.

13 David TE, Uden DE, Strauss HD. The importance of the mitral apparatus in left ventricular function after correction of mitral regurgitation. Circulation 1983;68(suppl II): $76-82$.

14 Yacoub M, Halim M, Radley-Smith R, McKay R, Nijveld $A$, Towers $M$. Surgical treatment of mitral regurgitation caused by floppy valves: Repair versus replacement. caused by floppy valves: Repair
Circulation 1981;64(suppl II):210-6.

Circulation 1981;64(suppl II):210-6.
15 Oliveira DB, Dawkins KD, Kay PH, Paneth M. Chordal rupture. II: comparison between repair and replacement. rupture. II: comparison betwe

16 Tepe NA, Edmunds LH Jr. Operation for acute postinfarction mitral insufficiency and cardiogenic shock. $J$ Thorac Cardiovasc Surg 1985;89:525-30.

17 Rankin JS, Feneley MP, Hickey MS, et al. A clinical comparison of mitral valve repair versus valve replacement in ischemic mitral regurgitation. J Thora Cardiovasc Surg 1988;95:165-77.

18 Hickey MSJ, Smith R, Muhlbaier LH, et al. Current prognosis of ischaemic mitral regurgitation: implication for future management. Circulation 1988;78(suppl I): 51-9.

19 Kay GL, Kay JH, Zubiate P, Yokoyama T, Mendez M. Mitral valve repair for mitral regurgitation secondary to coronary artery disease. Circulation 1986;74:188-98.
20 Craver JM, Cohen C, Weintraub WS. Case-matched comparison of mitral valve replacement and repair. Ann parison of mitral valve replac

21 Cohn LH, Kowalker W, Bhatia S, et al. Comparative morbidity of mitral valve repair versus replacement for mitral regurgitation with and without coronary artery disease. Ann Thorac Surg 1988;45:284-90.

22 Scott ML, Stowe CL, Nunnally LC, et al. Mitral valve reconstruction in the elderly population. Ann Therac Surg 1989;48:213-7.

23 Galloway AC, Colvin SB, Baumann FG, et al. Long-term results of mitral valve reconstruction with Carpentier techniques in 148 patients with mitral insufficiency. Circulation 1988;78(Suppl I):97-105.

24 Galler M, Kronzon I, Slater J, et al Long-term follow-up after mitral valve reconstruction: incidence of postafter mitral valve reconstruction: incidence of post1986;74:199-203.

25 Schiavone WA, Cosgrove DM, Lever HM, Stewart WJ, Salcedo EE. Long-term follow-up of patients with left ventricular outflow tract obstruction after Carpentier ring mitral valvuloplasty. Circulation 1988;78(suppl I):60-5.

26 Isom OW, Spencer FC, Glassman E, et al. Long-term results in 1,375 patients undergoing valve replacement with the Starr-Edwards cloth-covered steel ball prosthesis. Ann Surg 1977;186:310-23.

27 Spencer FC, Baumann FG, Grossi EA, Culliford AT, Galloway AC. Experiences with 1,643 porcine prosthetic Galloway AC. Experiences with 1,643 porcine prosth
valves in 1,492 patients. Ann Surg 1986;203:691-700. 